\title{
Is bone quality crucial in arthroplasty of the joints?
}

\author{
O. Şahap Atik, MD \\ President, Turkish Joint Diseases Foundation, Ankara, Turkey
}

Osteoporosis is a major health issue worldwide with considerable economic consequences and adverse effects on quality of life. ${ }^{[1]}$

In arthroplasties, poor bone quality (i.e., poor bone structure) and low bone mineral density, eventually weak bone strength is crucial for the survival of implants. For longer durability of the implants, these factors should be assessed further and efforts should be made to resolve them. ${ }^{[2]}$

The rates of bone production and destruction can be evaluated through a meticulous assessment of the bone matrix components released in the bloodstream and excreted in the urine. Biomarkers of formation include bone-specific alkaline phosphatase, osteocalcin and biomarkers of resorption: N-terminal and C-terminal cross-linking telopeptide of type I collagen. ${ }^{[3]}$

Osteoporosis in elderly patients is the main problem with the accompanying low bone quality, resulting in osseointegration failure in cementless fixation of the acetabular cup and femoral stem. ${ }^{[4-6]}$

Received: August 15, 2021

Accepted: September 25, 2021

Published online: November 19, 2021

Correspondence: O. Şahap Atik, MD. Turkish Joint Diseases Foundation, Mustafa Kemal Mah., Dumlupınar Bul., 274/2, C2 Blok, Ofis 5, 06900 Çankaya, Ankara, Türkiye.

E-mail: satikmd@gmail.com

Doi: $10.52312 /$ jdrs.2021.57902

Citation: Atik OS. Is bone quality crucial in arthroplasty of the joints?. Jt Dis Relat Surg 2021;32(3):824.

(92021 All right reserved by the Turkish Joint Diseases Foundation

This is an open access article under the terms of the Creative Commons Attribution-NonCommercial License, which permits use, distribution and reproduction in any medium, provided the original work is properly cited and is not used for commercial purposes (http://creativecommons.org/licenses/by-nc/4.0/).
Cement fixation of the implants is recommended to minimize the risk of peri-prosthetic fracture and aseptic loosening. ${ }^{[2]}$

In Medicare patients, cemented femoral fixation outperformed cementless fixation in terms of the length of hospital stay, readmission, cost of care, and reoperation. ${ }^{[7]}$

\section{Declaration of conflicting interests}

The author declared no conflicts of interest with respect to the authorship and/or publication of this article.

\section{Funding}

The author received no financial support for the research and/or authorship of this article.

\section{REFERENCES}

1. Atik OŞ, Aslan A, Odluyurt M. Are fragility fractures being treated properly? Jt Dis Relat Surg 2020;31:403-4.

2. Kobayashi S, Saito N, Horiuchi H, Iorio R, Takaoka K. Poor bone quality or hip structure as risk factors affecting survival of total-hip arthroplasty. Lancet 2000;355:1499-504.

3. Atik OŞ, Sezgin EA, Tepedelenlioğlu HE. The role of biomarkers in osteoarthritis and osteoporosis for early diagnosis and monitoring prognosis. Eklem Hastalik Cerrahisi 2019;30:175-6.

4. Atik OŞ, Çankaya D. To cement or not to cement, that is the question in elderly! Jt Dis Relat Surg 2021;32:277-8.

5. Jämsen E, Eskelinen A, Peltola M, Mäkelä K. High early failure rate after cementless hip replacement in the octogenarian. Clin Orthop Relat Res 2014;472:2779-89.

6. Song JSA, Dillman D, Wilson D, Dunbar M, Richardson G. Higher periprosthetic fracture rate associated with use of modern uncemented stems compared to cemented stems in femoral neck fractures. Hip Int 2019;29:177-83.

7. Oh JH, Yang WW, Moore T, Dushaj K, Cooper HJ, Hepinstall MS. Does femoral component cementation affect costs or clinical outcomes after hip arthroplasty in Medicare patients? J Arthroplasty 2020;35:1489-96.e4. 